\title{
Enzymatic reduction and oxidation of fibre-bound azo-dyes
}

\author{
S. Pricelius ${ }^{a}$, C. Held ${ }^{\text {a }}$, S. Sollner ${ }^{b}$, S. Deller ${ }^{\text {b }}$, M. Murkovic ${ }^{\text {c }}$, R. Ullrich $^{\text {d }}$, \\ M. Hofrichter ${ }^{\mathrm{d}}$, A. Cavaco-Paulo ${ }^{\mathrm{e}}$, P. Macheroux ${ }^{\mathrm{b}}$, G.M. Guebitz ${ }^{\mathrm{a}, *}$ \\ ${ }^{a}$ Department of Environmental Biotechnology, Graz, University of Technology, Petersgasse 12, 8010 Graz, Austria \\ ${ }^{\mathrm{b}}$ Department of Biochemistry, Graz University of Technology, Petersgasse 12, 8010 Graz, Austria \\ ${ }^{\mathrm{c}}$ Department of Food Chemistry and Technology, Graz University of Technology, Petersgasse 12, 8010 Graz, Austria \\ ${ }^{\mathrm{d}}$ Chair of Environmental Biotechnology, International Graduate School Zittau, Germany \\ e Department of Textile Engineering, University of Minho, 4800 Guimaraes, Portugal
}

Received 12 August 2006; received in revised form 3 November 2006; accepted 3 November 2006

\begin{abstract}
A new customer and environmental friendly method of hair bound dye decolouration was developed. Biotransformation of the azo-dyes Flame Orange and Ruby Red was studied using different oxidoreductases. The pathways of azo dye conversion by these enzymes were investigated and the intermediates and metabolites were identified and characterised using UV-vis spectroscopy, high-performance liquid chromatography (HPLC) and mass spectrometry (MS). Laccase from Pycnoporus cinnabarinus, manganese peroxidase (MnP) from Nematoloma frowardii and the novel Agrocybe aegerita peroxidase $(\mathrm{AaP})$ were found to use a similar mechanism to convert azo dyes. They $N$-demethylated the dyes and concomitantly polymerized them to some extent. On the other hand the mechanism for cleavage of the azo bond by azo-reductases of Bacillus cereus and B. subtilis was based on reduction of the azo bond at the expense of $\mathrm{NAD}(\mathrm{P}) \mathrm{H}$.
\end{abstract}

(C) 2006 Elsevier Inc. All rights reserved.

Keywords: Azo dye; Hair; Azoreductase; Laccase

\section{Introduction}

Azo dyes are widely used in industry and daily life, for example, as components in permanent hair dyes. Additionally, azo-compounds represent the largest class of dyes applied in the textile, food, and cosmetic industries. Azo dyes used as components in permanent hair dyes can only be decolorized by drastical methods such as chemical bleaching using hydrogen peroxide. However, this treatment may cause hair damage and health problems. Hence, the use of these methods requires extreme precautions in order to prevent these adverse effects. Therefore, it would be useful to develop a customer friendly and safe treatment method avoiding the use of hazardous chemicals. Enzymes that specifically oxidize or reduce azo-bonds and, thereby, decolorize dyed hair could be an elegant alternative since they can be used under mild conditions and they do not have negative effects both on hair and skin.

\footnotetext{
* Corresponding author.

E-mail address: guebitz@ tugraz.at (G.M. Guebitz).
}

Azo dyes are quite resistant to biological degradation [1] but, nevertheless, decolorization in aerobic, anaerobic, anoxic or combined treatment processes have been reported [2-5]. Several mircroorganisms produce enzymes which reductively cleave the azo bond at the expense of a reducing agent, typically $\mathrm{NAD}(\mathrm{P}) \mathrm{H}$. The occurrence of these so-called azo-reductases has been reported for a number of bacteria. Recently, we have shown that an azo-reductase from a thermoalkalophilic Bacillus sp. was able to reduce a large structural variety of systematically substituted azo dyes [6]. The non-specificity of the azo-reductase reaction was also demonstrated in several reports on the decolorization of azo dyes by sewage sludge under anaerobic conditions $[1,7,8]$. It seems that almost all azo compounds tested are biologically reduced under anaerobic conditions, although there are some indications that metal-ion-containing dyes sometimes have lower decolorization rates [9]. Cell extracts show usually much higher rates for anaerobic reduction of azo dyes than preparations of resting cells do [4]. This has generally been explained by the low permeability of the cell membranes for the azo-compounds [10].

Azo-dyes are also degraded efficiently under aerobic conditions by wood-rotting fungi (e. g. Phanerochaete chrysosporium, 
Trametes spp.) which are in nature responsible for the degradation of lignin [11]. While fungal treatment of dye containing effluents is usually time-consuming and difficult to control [2], the potential of enzymes for this purpose has clearly been demonstrated. The enzymes involved in the degradation of azo dyes are mainly peroxidases [12] and laccases [13].

Laccases are benzenediol: oxygen oxidoreductases (EC 1.10.3.2) and belong to the family of blue copper proteins. Reactions of laccase include one-electron oxidations of phenolic and aminoaromatic substrates and can lead to reactive free radicals (e.g. phenoxyl radicals), which undergo further polymerization, depolymerization, demethylation, quinone formation and ring cleavage of aromatic compounds [14]. In a number of studies, laccases were successfully used to decolorize different industrial dyes, thereby showing a broad substrate specificity [15-17].

Similarly, degradation of different dyes was achieved with crude or purified manganese peroxidase (MnP; EC 1.11.1.13) $[18,19] . \mathrm{MnP}$ is a heme-containing glycoprotein that requires hydrogen peroxide as an oxidant [20] and catalyzes the cleavage of phenolic lignin model compounds as well as of non-phenolic lignin moieties when supplied with suitable co-oxidants (redoxmediators) [21]. The activity of $\mathrm{MnP}$ is strictly dependent on chelating organic acids (e.g. oxalate, malonate), $\mathrm{H}_{2} \mathrm{O}_{2}$ and $\mathrm{Mn}^{2+}$ [22].

In addition to $\mathrm{MnP}$ and laccase, other fungal enzymes could have a potential for dye decolorization as well. Recently a novel haloperoxidase cytochrome-P450 hybrid (AaP; EC 1.11.1.10) has been isolated the agaric basidiomycete A. aegerita. AaP requires $\mathrm{H}_{2} \mathrm{O}_{2}$ to oxidize, among others, aryl alcohols into the corresponding aldehydes and then further into benzoic acids.

In this study, we show for the first time that two azocompounds used in commercially important hair dyes are susceptible to enzymatic reduction and oxidation with concomitant decolorization, even when bound to hair.

\section{Methods}

\subsection{Chemicals and enzymes}

The azo dyes Flame Orange and Ruby Red were supplied from CIBA and are used as components in permanent hair dyes (see Fig. 1). All other chemicals used were analytical grade and purchased from Sigma.

Manganese peroxides (MnP) of Nematoloma frowardii (specific activity $19 \mathrm{U} \mathrm{mg}^{-1}$ ) and laccase of Pycnoporus cinnabarinus $\left(84.2 \mathrm{U} \mathrm{ml}^{-1}\right)$ were purchased from JenasBios GmbH (Jena, Germany). Agrocybe aegerita peroxidase

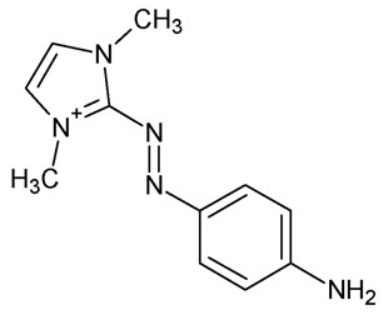

Flame Orange

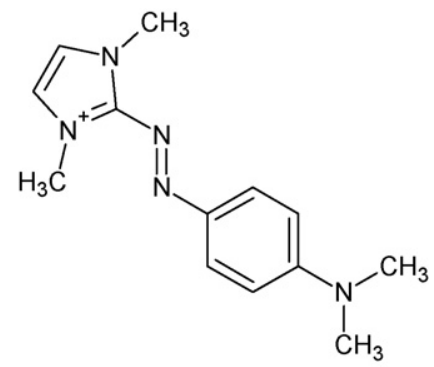

Ruby Red
(AaP) $\left(80.9 \mathrm{U} \mathrm{ml}^{-1}\right)$ was produced and purified as described by Ullrich et al. [27].

The flavin-containing NADH- and/or NADPH dependent oxidoreductases of B. subtilis YcnD and YhdA, were prepared as previously reported [24].

The azo-reductases from Bacillus cereus and B. subtilis were produced by growing them for $12 \mathrm{~h}$ in 11 baffled Erlenmeyer flasks on a rotary shaker at $160 \mathrm{rpm}$ and $38^{\circ} \mathrm{C}$ in $500 \mathrm{ml}$ standard I nutrient medium (Merck). Cells were harvested by centrifugation for $15 \mathrm{~min}$ at $3000 \times g$ and the pellet was re-suspended in $50 \mathrm{mM}$ sodium phosphate buffer, $\mathrm{pH} 7.0$ ( $2 \mathrm{ml}$ buffer per gram of wet cell paste). Cell lysis was done with a French press (American Instrument Company, Maryland, USA), performing three passes. The cell debris was removed by centrifugation at $34,000 \times g$ for $60 \mathrm{~min}$ at $4{ }^{\circ} \mathrm{C}$ and the supernatant was filtered through a prefilter (Glass Fiber Filter with binder, AP20, $75 \mathrm{~mm}$, Millipore, Billerica, USA), a $45 \mu \mathrm{m}$ filter with pressure filtration and through a Minisart single use syringe filter sterile EO using a $0.2 \mu \mathrm{m}$ membrane (Sartorius, Hannover, Germany). Crude extracts were further purified by using a combination of ammonium sulphate precipitation and anion exchange chromatography as reported by Maier et al. [6].

\subsection{Enzyme assays}

Assays were carried out in cuvettes with a total volume of $1 \mathrm{ml}$. One unit of enzyme activity was defined as the amount of enzyme that transformed $1 \mu \mathrm{mol}$ of substrate per minute $(=1$ unit $=1 \mathrm{U})$.

\subsubsection{Assay for azo-reductase activity, $Y c n D$ and $Y h d A$}

The reaction mixture contained $400 \mu \mathrm{l}$ of $50 \mathrm{mM}$ sodium phosphate buffer ( $\mathrm{pH} 7.0$ ), $200 \mu \mathrm{l}$ of the sample and $200 \mu \mathrm{l}$ of the azo dye Cibacrone Marine $\left(100 \mathrm{mg}^{-1}\right)$. The reaction was initiated by the addition of $200 \mu \mathrm{lNADH}$ (7.09 $\mathrm{mg} \mathrm{ml}^{-1}$, final concentration $2 \mathrm{mM}$ ) and followed photometrically at $595 \mathrm{~nm}$. The slope of the initial linear decrease of absorption was used to calculate the enzyme activity based on the molar absorption coefficient of Cibacrone Marine $\left(\varepsilon_{595}=35.5 \mathrm{mmol}^{-1} \mathrm{~cm}^{-1}\right)$ as described by Maier et al. [6].

\subsubsection{Assay for laccase activity}

Laccase activity was determined using 2,2'-azino-di-(-3-ethylbenzothiazoline-6-sulfonic acid) (ABTS) as the substrate. Five hundred microliter of $50 \mathrm{mM}$ citrate buffer ( $\mathrm{pH} 4.0$ ) was mixed with $430 \mu \mathrm{l}$ of distilled water and $20 \mu \mathrm{l}$ of laccase. The reaction was started by the addition of $50 \mu \mathrm{l}$ of $6 \mathrm{mM}$ ABTS and the increase in absorbance at $436 \mathrm{~nm}$ was monitored. The enzyme activity was calculated using an extinction coefficient of ABTS of $\varepsilon_{436}=36 \mathrm{mmol}^{-1} \mathrm{~cm}^{-1}$ [25].

\subsubsection{Assay for $M n P$ activity}

The reaction mixture contained $500 \mu \mathrm{l}$ of $50 \mathrm{mM}$ sodium malonate buffer (pH 4.5), $25 \mu \mathrm{l}$ of $20 \mathrm{mM} \mathrm{MnCl}_{2}$ solution, $415 \mu \mathrm{l}$ of distilled water and $50 \mu \mathrm{l}$ of MnP. The reaction was started by adding $20 \mu 110 \mathrm{mM} \mathrm{H}_{2} \mathrm{O}_{2}$. The extinction of the solution was measured photometrically at the wavelength $270 \mathrm{~nm}$ $\left(\varepsilon_{270}=11.59 \mathrm{mmol}^{-1} \mathrm{~cm}^{-1}\right)[26]$.

\subsubsection{Assay for AaP activity}

The activity of AaP was measured photometrically at $310 \mathrm{~nm}$ by monitoring the oxidation of veratryl alcohol into veratraldehyde $\left(\varepsilon_{310}=9.3 \mathrm{mmol}^{-1} \mathrm{~cm}^{-1}\right)$ [23]. The reaction was carried out at $\mathrm{pH} 7$ in $500 \mu 1$ potassium phosphate buffer (50 mM), $100 \mu \mathrm{l}$ of $50 \mathrm{mM}$ veratraldehyde, $370 \mu \mathrm{l}$ distilled $\mathrm{H}_{2} \mathrm{O}, 20 \mu \mathrm{l} \mathrm{AaP}$ and was started by addition of $2 \mathrm{mM} \mathrm{H}_{2} \mathrm{O}_{2}$.

\subsubsection{Dye biotransformation studies}

Biotransformation of dyes was carried out in cuvettes containing $0.1 \mathrm{U} \mathrm{ml}^{-1}$ YcnD, YhdA or azo-reductase from crude cell extract of B. cereus and $B$. subtilis, respectively, $200 \mu \mathrm{g} \mathrm{ml}^{-1}$ dye $7 \mathrm{mM} \mathrm{NADH}$ in $50 \mathrm{mM}$ sodium phosphate buffer (pH 7.0). Decolorization was monitored at $\lambda_{\max }$ of the dyes. The dyes were treated with $1 \mathrm{U} \mathrm{ml}^{-1}$ of $\mathrm{MnP}$ in the presence or absence of $5 \mathrm{mM}$ Gluthation (GSH), AaP and laccases in the presence or absence of $1 \mathrm{mM} 1$ hydroxybenzotriazole (HBT) and stirred for $1 \mathrm{~h}$ at $20^{\circ} \mathrm{C}$. Controls were run without addition of enzymes.

Fig. 1. Structure of Flame Orange and Ruby Red. 
Decolorization of dyed hair was carried out in $1 \mathrm{ml}$ Eppendorf plastic tubes on a Thermomixer comfort (Eppendorf AG, Hamburg, Germany) set to $35^{\circ} \mathrm{C}$. The incubation mixture contained $5 \mathrm{mg}$ of hair that was dyed with Flame Orange or Ruby Red, $0.1 \mathrm{U} \mathrm{ml}^{-1} \mathrm{YcnD}$, YhdA or azo-reductase of crude cell extract from B. cereus, B. subtilis, $7 \mathrm{mM}$ NADH $(7 \mathrm{mM})$ in $1 \mathrm{ml} 50 \mathrm{mM}$ sodium phosphate buffer (pH 7.0)

\subsection{High-performance liquid chromatography (HPLC) and mass spectrometry $(M S)$ analyzes}

Dye conversion products were separated by an HPLC system equipped with a C18 column (Amersham Biosciences Europe GmbH, Vienna, Austria) with acetonitrile and $15 \mathrm{mM} \mathrm{H}_{3} \mathrm{PO}_{4}, 10 \mathrm{mM} \mathrm{H}_{2} \mathrm{SO}_{4}$ and distilled water as the mobile phase at a flow rate of $1 \mathrm{ml} \mathrm{min}^{-1}$ at $40^{\circ} \mathrm{C}$. Water was distilled twice and filtered through a $0.45 \mu \mathrm{m}$ Millipore filter and degassed prior to use.

Dionex HPLC system (Dionex Corporation, Sunnyvale, CA) consisting of a P580 pump, ASI-100 automated sample injector and a PDA-100 photodiode array detector was used with the following operating conditions: injection volume, $10 \mu \mathrm{l}$; column temperature, $40^{\circ} \mathrm{C}$; detection wavelength was chosen according to the absorbance maxima for the azo dyes (Flame Orange: $486 \mathrm{~nm}$; Ruby Red: $526 \mathrm{~nm}$ in addition at 210, 220 and $300 \mathrm{~nm}$ ). The mobile phase was a degassed mixture of $\mathrm{A}$, double distilled water and $\mathrm{B}$, acetonitrile under isocratic conditions ranging from 8 to $25 \%$ depending on the dye.

For the detection of degradation products of Flame Orange after reductase treatment, the mobile phase consisted of $\mathrm{B}, 14 \% ; 10 \mathrm{mM} \mathrm{H}_{2} \mathrm{SO}_{4}, 50 \%$; and $36 \%$ of mobile phase A. For the degradation products of Ruby Red, the mobile phases were $\mathrm{B}, 25 \% ; 10 \mathrm{mM} \mathrm{H}_{2} \mathrm{SO}_{4}, 30 \%$; and $\mathrm{A}, 45 \%$.

For analysis of degradation products of Flame Orange after oxidase treatment the mobile phase consisted of $\mathrm{B}, 8 \%, 82 \% 15 \mathrm{mM} \mathrm{H}_{3} \mathrm{PO}_{4}$ and for the degradation products of Ruby Red were detected in: $\mathrm{B}, 20 \%, 80 \% \mathrm{H}_{3} \mathrm{PO}_{4}$. UV-vis-spectra were recorded (DAD detection) and peak heights were compared with those of authentic standards.

The MS analysis was done on an Agilent MSD (Waldbronn, Germany) with direct injection using the following parameters: Drying gas temperature $350^{\circ} \mathrm{C}$, drying gas pressure $40 \mathrm{psi}$, drying gas flow (nitrogen) $101 \mathrm{~min}^{-1}$, capillary voltage $3500 \mathrm{~V}$, fragmentor voltage $70 \mathrm{~V}$, mass range $70-400 \mathrm{~m} / \mathrm{z}$. The data were analyzed using the software Chemstation Rev. A 10.01 (Agilent, Waldbronn, Germany). For measurement in positive mode $0.01 \%$ acetic acid was added. To check for fragments formed during the massmetry, the fragmentor voltage was set from 25 to $150 \mathrm{~V}$.

\section{Results}

\subsection{UV-vis absorbance spectrometry and mass spectrometry}

Our studies have demonstrated that Ruby Red and Flame Orange were completely decolorized by Ycnd, YhdA and azoreductases prepared from Bacillus strains (Fig. 2). A color change from red to orange was observed when Ruby Red was treated with laccase, MnP and AaP. When Flame Orange was treated with these oxidases the color changed to pale yellow with a hypsochromic shift of the absorbance maximum from 486 to $390 \mathrm{~nm}$ but no complete decolorization could be observed.

Interestingly, fibre bound Ruby Red and Flame Orange (dyed human hair) were also completely decolorized as shown in Fig. 3. The spectrophotometric data were confirmed by HPLC analyzes. Complete decolorization of Flame Orange and Ruby Red by YhdA, YcnD and Bacillus-derived azo-reductases lead to several highly polar transformation products with a retention time of less than $1 \mathrm{~min}$. The faster eluting intermediates absorbed in the UV-region. The chromatographic peaks of several target

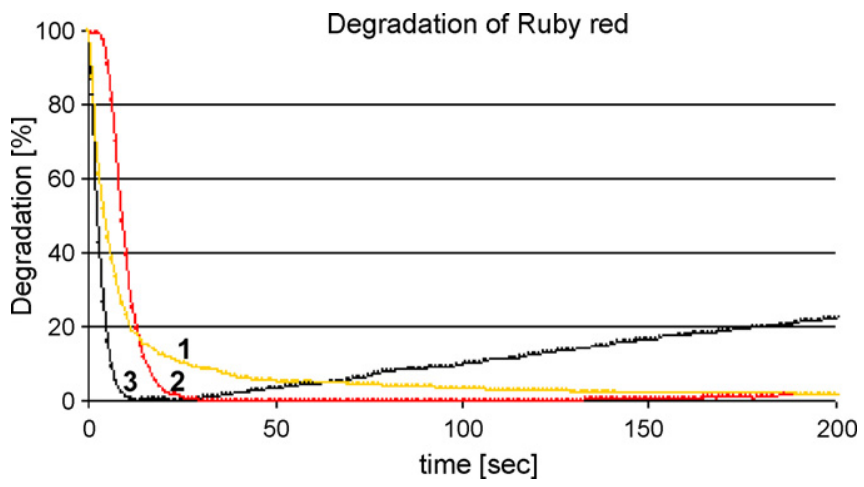

Fig. 2. Conversion of Ruby Red with YhdA [1], YcnD [2] and the azo-reductase of B. cereus [3].

compounds overlapped, but the gradient program could not be optimized in such a way that it was possible to analyze intermediates in detail. The peaks corresponding to Flame Orange and Ruby Red disappeared completely indicating full conversion of the azo dyes under the experimental conditions (incubation for 15 min with YhdA, YcnD and the azo-reductase from B. cereus or B. subtilis).

HPLC analysis of Ruby Red treated with laccase, MnP and AaP indicated, that Ruby Red was transformed to extents of 15, 35 and to $23.5 \%$, respectively after $1 \mathrm{~h}$ and to 98,96 and $48 \%$ after $20 \mathrm{~h}$, respectively. The further analysis showed that laccase, $\mathrm{MnP}$ and AaP treatment of Ruby Red led to two intermediates. The highest amount of a product with retention time of $4.1 \mathrm{~min}$ was seen after $20 \mathrm{~h}$ while this product disappeared totally after $3 \mathrm{~d}$. This observation led to the conclusion that the initial product was a transient intermediate, which underwent further transfor-

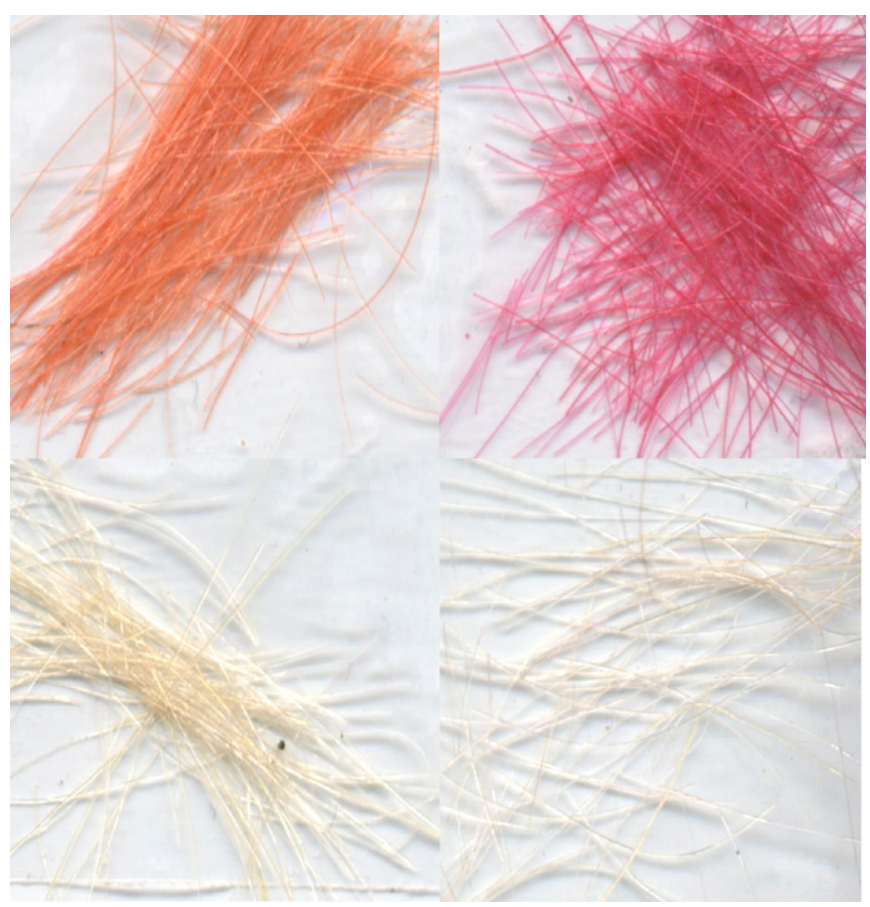

Fig. 3. Decolorization of hair bound Flame Orange and Ruby Red by azoreductase from B. cereus. 
Table 1

Conversion of Ruby Red and Flame Orange with laccase $\left(1 \mathrm{U} \mathrm{ml}^{-1}\right)$ and $\mathrm{MnP}$ $\left(1 \mathrm{U} \mathrm{ml}^{-1}\right)$ with and without redox-mediator (HBT, GSH) for $1 \mathrm{~h}$

\begin{tabular}{llcl}
\hline Enzyme & Azo dye & $\begin{array}{l}\text { Conversion without } \\
\text { mediator }(\%)\end{array}$ & $\begin{array}{l}\text { Conversion with } \\
\text { mediator }(\%)\end{array}$ \\
\hline Laccase & Ruby Red & 13.70 & 100 \\
& Flame Orange & 1.46 & 100 \\
\multirow{2}{*}{$\mathrm{MnP}$} & Ruby Red & 31.62 & 62.74 \\
& Flame Orange & 6.6 & 19.9 \\
\hline
\end{tabular}

mation to a final product. Using standards, this transient product was identified as Flame Orange.

Flame Orange was only slightly oxidized by laccase, $\mathrm{MnP}$ or $\mathrm{AaP}$ but the conversion was considerably enhanced in the presence of redox-mediators such as HBT or glutathione (GSH) at low concentrations as shown in Table 1.

\subsection{Mass spectrometry}

To exclude the possibility of spontaneous dye conversion during MS analysis, standards of Ruby Red and Flame Orange were analyzed as well. The reaction products of Ruby Red with laccase are shown in Fig. 4 and indicate that laccase is able to demethylate the dye. One of the main degradation products had an $\mathrm{m} / \mathrm{z}$ of 231 which is subject to a second demethylation event to give rise of a $\mathrm{m} / \mathrm{z}$ peak of 216 . This $\mathrm{m} / \mathrm{z}$ is identical to Flame Orange $(\mathrm{m} / \mathrm{z}$ of 216$)$ and confirms the results from HPLC analysis (see before). The same major degradation products were formed when Ruby Red was treated with $\mathrm{MnP}$ or AaP.

Interestingly, treatment of Ruby Red with different oxidoreductases does not result in the same pattern degradation products. Thus, different degradation pathways seem to exist for this dye depending whether laccase, $\mathrm{MnP}$ or AaP is used. These pathways, however, were not further elucidated in this study since none of these enzymes caused the complete decolorization of the dyes.

Reduction of azo-compounds by azo-reductases from $B$. cereus and $B$. subtilis should lead to the corresponding aromatic amines [6]. Indeed, the mass spectra of the reduction products indicated reduction of Ruby Red to the corresponding amines. As shown in Fig. 5, $N \sim 1 \sim, N \sim 1 \sim$-dimethyl-1,4benzenediamine with a molecular mass of 136 and 2-amino-1,3 dimethylimidazolium with a mass of 112 were formed. When Ruby Red was treated with azo-reductases, YhdA and YcnD, a decrease of the compounds with the $m / z$ of 148 and 244 (the original dye) was observed with increasing incubation time (samples taken at 5, 10, 20,30 s). Concomitantly, an increase of the $\mathrm{m} / \mathrm{z}$ of 112,122 and 136 was observed. No other significant peak was found in the mass spectra of any of the two dyes tested, i.e. by-products were not formed at significant concentrations in the course of the reaction.

When Flame Orange was treated with azo-reductases, YhdA and YcnD, only an increase of the compound with the $\mathrm{m} / \mathrm{z}$ of 112 ascribed to 2-amino-1,3 dimethylimidazolium was seen in the course of the experiment while the amount of the degradation product $m / z 216$ (the original dye) decreased concomitantly. The expected compound with the $\mathrm{m} / \mathrm{z}, 108$ (1,4-benzenediamine) was not detected. However, as demonstrated by using a standard of 1,4-benzenediamine, this compound is not stable under the experimental conditions (MS) and several coupling reactions could have taken place. Azo-reductases from both B. cereus and B. subtilis and $\mathrm{YcnD}$, YhdA formed the same degradation products, thus it can be assumed that the reductive reactions follow a similar mechanism.

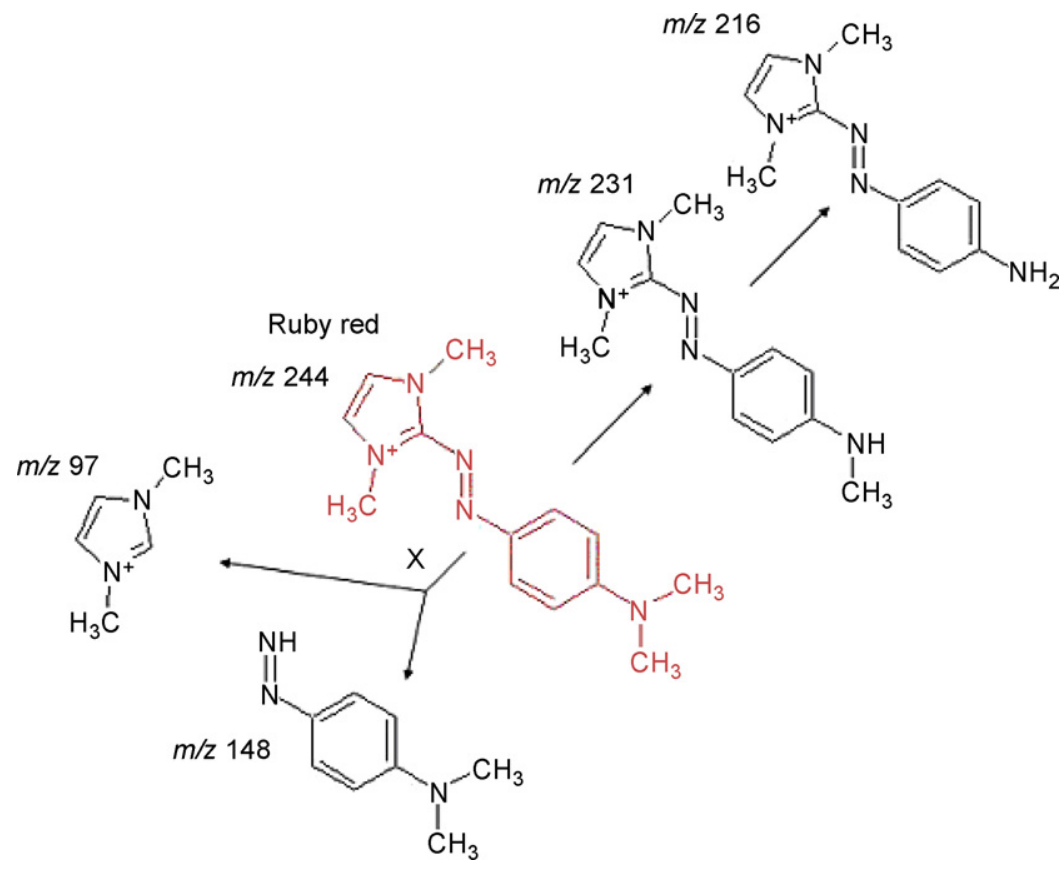

Fig. 4. Transformation products of Ruby Red treated with laccase, MnP or AaP as detected by MS. X indicates reactions caused by MS. 


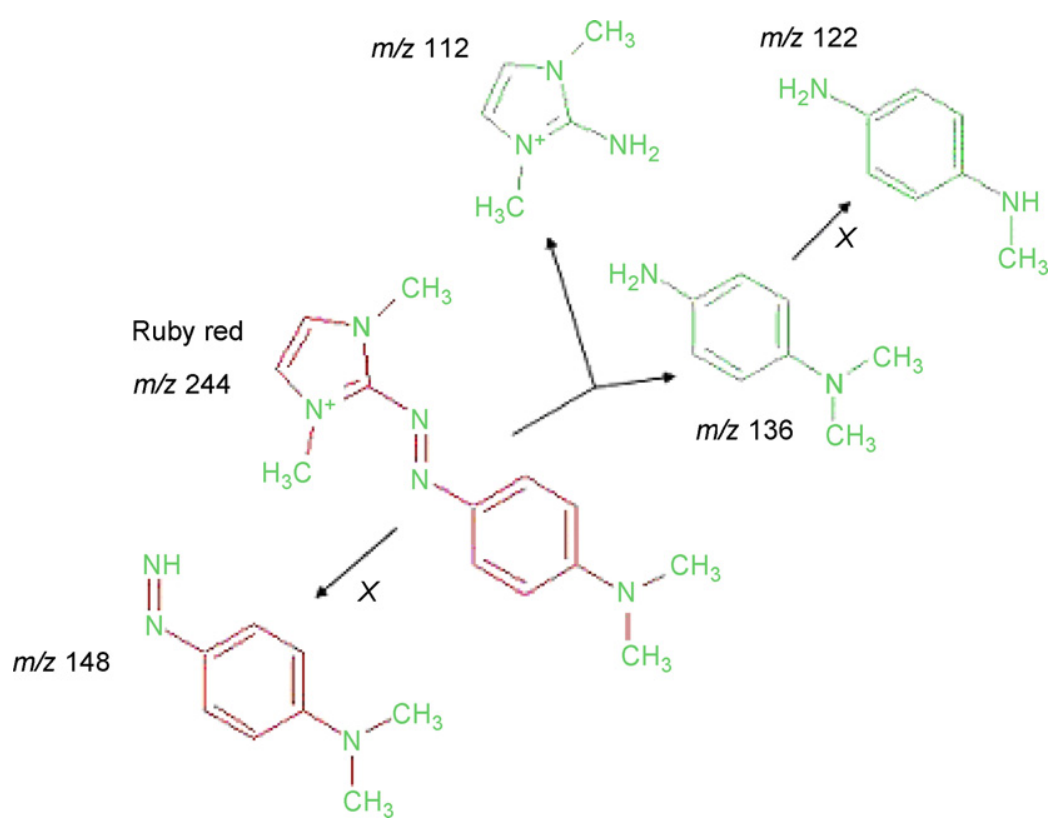

Fig. 5. Transformation products of Ruby Red treated with azo-reductases, YhdA or YcnD, as detected by MS. X indicates reactions caused by MS as confirmed with standard compounds.

\section{Discussion}

In this study, we have demonstrated that biotransformation of the azo-hair-dyes Flame Orange and Ruby Red can be achieved both by reductases and (per)oxidases, and that a fibre-bound dye is also enzymatically transformed. Several previous studies have shown that the initial step in the biodegradation of azodyes under anaerobic conditions is a reductive cleavage of the azo bond at the expense of NADH or NADPH serving as electron donors for the reaction $[6,9,27,28]$. This process is catalysed by soluble cytosolic enzymes with low substrate specificity known as azo-reductases. Molecular oxygen competes for the available reducing equivalents with the azo dyes and slows down the reductive cleavage of the azo bond [29].

As previously shown for other azo dye degrading microorganisms, decolorization of the azo-dyes Ruby Red and Flame Orange only occurred in the presence of NADH or NADPH as a cosubstrate. When Ruby Red was used as a target structure for reductive cleavage, 2-amino-1,3 dimethylimidazolium and $N \sim 1 \sim, N \sim 1 \sim$-dimethyl-1,4-benzenediamine could be detected by MS upon treatment with the purified azo-reductases, YhdA and YcnD. This clearly demonstrates that azo bond cleavage occurs in the presence of an azo-reductase. In the case of Flame Orange, however, the products expected from reductive cleavage could not be observed probably due to auto-oxidation of the 1,4-benzenediamine as previously suggested [10]. Hence, we propose that the dye decolorizing enzymes of $B$. subtilis and $B$. cereus convert azo dyes by cleaving the azo bond leading to the free amines. Under anoxic conditions these enzymes facilitate the transfer of electrons via NADH to the azo dye which is then reduced. The hypothesis that YhdA acts as an azo-reductase that converts the dyes via the symmetric cleavage of the azo bond (unlike laccase $\mathrm{MnP}$ and $\mathrm{AaP}$ ) could be confirmed by the observation of $N \sim 1 \sim, N \sim 1 \sim$-dimethyl-1,4benzenediamine and 2-amino-1,3 dimethylimidazolium, when Ruby Red was treated with YhdA. As described by Morokutti et al. [24], azo-dyes do not enter the active site of YcnD and reduction of the dye is mediated by free reduced Riboflavin $5^{\prime}$ monophosphate sodium salt dehydrate (FMN), which in turn is generated by NADH dependent reduction in the active site of the enzyme. The reduction rate decreased when methyl groups as electron donating substituents were introduced into the dye, like in Ruby Red, but the reaction pathway was the same. Thus, earlier results obtained by Zimmermann et al. [28] were confirmed that decolorization of azo dyes with azoreductases can be enhanced with electron withdrawing groups at the aromatic ring, especially ortho-substitutions show this effect [6]. Furthermore, it was reported that substrates with an electron-negative substituent at the phenyl ring would enhance the enzyme reaction rate. This effect may be due to the fact that $\mathrm{e}^{-}$-withdrawing groups lead to a decreased electron density at the $\mathrm{N}=\mathrm{N}$ double bond. Hence, electron transfer to this group is released.

Besides reductive cleavage, it is generally assumed that peroxidases such as $\mathrm{MnP}$ and $\mathrm{AaP}$ as well as laccases, catalyzing the depolymerization of lignin, are also involved in the initial oxidation of a wide range of other recalcitrant compounds including different azo-dyes [19,12]. Recently it was shown that certain MnPs and laccases can convert commercial azo-dyes, such as Reactive Black 5 [18]. The ability of these enzymes to chemically transform such a range of organic compounds results from their low specificity and the involvement of free radicals. Although in this study, laccase from Pycnoporus cinnaburinus, $\mathrm{MnP}$ from Nematoloma fromardii and haloperoxidase from Agrocybe aegerita caused significant changes in the colour of the dyes Flame Orange and Ruby Red, they could not 
decolorize them completely. Interestingly, Ruby Red was decolorized much faster than Flame Orange. One possible reason for this observation may be the lack of the slightly electrondonating effect of the two methyl groups at the nitrogen atom, which may render the molecule more susceptible towards oxidation by enzymes. These results confirm earlier observations reported by Chivukula and Renganathan [14] who suggested that the azo dye has to be electron rich for oxidation by an (per)oxidase. However, an interpretation of the substrate specificity solely based on the molecular structure of the parent compound may be misleading, and other effects, e.g. caused by reaction intermediates should be taken into consideration as well.

HPLC analysis of Ruby Red oxidation products indicated the presence of two reaction products. Laccases, $\mathrm{MnP}$ and $\mathrm{AaP}$ do not only degrade the original dye but attack the formed intermediates as well. According to Chivukula and Renganathan [14] laccases and peroxidases appear to utilize a similar mechanism for azo-dye oxidation. This finding was confirmed in the present study, even though the enzymes showed different conversion rates for Ruby Red and Flame Orange. Goszcynski et al. [12] proposed mechanisms, in the course of which laccases and peroxidases convert the dyes to cation radicals, being susceptible to nucleophilic attack by water or hydrogen peroxide. This results in further depolymerization, repolymerization and demethylation and finally leads to more stable intermediates. All peroxidases tested were able to demethylate Ruby Red resulting in the formation of Flame Orange, which went through further spontaneous reactions.

\section{Conclusion}

The main interest of this study has been the development of an enzymatic method for the irreversible decolorization of the two azo-dyes, Flame Orange and Ruby Red, with oxidative and reductive biocatalysts. The analysis of unknown reaction products revealed the formation of two major intermediates in samples treated with laccase, $\mathrm{MnP}$ or AaP. MS analyzes strongly indicated that these products resulted from enzymatic $N$-demethylation; cleavage of the azo-bond was not observed. The conversion mechanism of azo-reductases is likely based on the reduction and cleavage of the azo-bond resulting in the formation and accumulation of colourless aromatic amines. Hair bound azo dyes were also decolorized by the reductases.

\section{Acknowledgement}

The authors wish to thank K.-U. Schöning and F. Kaufmann from CIBA SC, Basel, Switzerland for the good cooperation within this project.

\section{References}

[1] Zollinger H. Colour chemistry Syntheses, Properties and Applications of Organic Dyes and Pigments. Weinheim: VCH Publishers; 1987.
[2] Banat IM, Nigam P, Singh D, Marchant R. Microbial decolorization of textile-dye-containing effluents: a review. Bioresour Technol 1996:217-27.

[3] Bragger JL, Lloyd AW, Soozandehfar SH, Bloomfield SF, Marriot C, Martin GP. Investigations into the azo reducing activity of a common colonic microorganism. Int J Pharm 1997:61-71.

[4] Wuhrmann K, Mechsner K, Kappeler T. Investigation on rate-determining factors in the microbial reduction of azo dyes. Eur J Appl Microbiol Biotechnol 1980:325-38.

[5] Rafii F, Franklin W, Cerniglia CE. Azoreductase activity of anaerobic bacteria isolated from human intestinal microflora. Appl Environ Microbiol 1990:2146-51.

[6] Maier J, Kandelbauer A, Erlacher A, Cavaco-Paulo A, Gubitz GM. A new alkali-thermostable azoreductase from Bacillus sp. strain SF. Appl Environ Microbiol 2004:837-44.

[7] Carliell CM, Barclay SJ, Naidoo N, Buckley CA, Mulholland DA, Senior E. Anaerobic decolorisation of reactive dyes in conventional sewagetreatment processes. Water SA 1994:341-4.

[8] Moutaouakkil A, Zeroual Y, Dzayri FZ, Talbi M, Lee K, Blaghen M. Purification and partial characterization of azoreductase from Enterobacter agglomerans. Arch Biochem Biophys 2003:139-46.

[9] Chung KT, Stevens SE. Degradation of azo dyes by environmental microorganism and helminthes. Environ Toxicol Chem 1993;12:2121-32.

[10] Russ R, Rau J, Stolz A. The function of cytoplasmic Flavin reductases in the reduction of azo dyes by bacteria. Appl Environ Microbiol 2000: 1429-34.

[11] David PB, Steven DA. Mechanism White Rot Fungi use to degrade pollutants. Environ Sci Technol 1994:78-87.

[12] Goszczynski S, Paszczynski A, Pastigrigsby MB, Crawford RL, Crawford DL. New pathway for degradation of sulfonated azo dyes by microbial peroxidases of Phanerochaete-chrysosporium and Streptomyceschromofuscus. J Bacteriol 1994:1339-47.

[13] Abadulla E, Robra H, Gübitz G, Silva L, Cavaco-Paulo A. Enzymatic decolorisation of textile dyeing effluents. Textile Res J 2000;70:409-14.

[14] Chivukula M, Renganathan V. Phenolic azo-dye oxidation by Laccase from Pyricularia-Oryzae. Appl Environ Microbiol 1995:4374-7.

[15] Wesenberg D, Kyriakides I, Agathos SN. White-rot fungi and their enzymes for the treatment of industrial dye effluents. Biotechnol Adv 2003:161-87.

[16] Cameselle C, Pazos M, Lorenzo M, Sanroman MA. Enhanced decolourisation ability of laccase towards various synthetic dyes by an electrocatalysis technology. Biotechnol Lett 2003:603-6.

[17] Tauber MM, Guebitz GM, Rehorek A. Degradation of azo dyes by laccase and ultrasound treatment. Appl Environ Microbiol 2005:2600-7.

[18] Heinfling A, Martinez MJ, Martinez AT, Bergbauer M, Szewzyk U. Transformation of industrial dyes by manganese peroxidases from Bjerkandera adusta and Pleurotus eryngii in a manganese-independent reaction. Appl Environ Microbiol 1998:2788-93.

[19] Pastigrigsby MB, Paszczynski A, Goszczynski S, Crawford DL, Crawford RL. Influence of aromatic-substitution patterns on azo dye degradability by Streptomyces spp. and Phanerochaete-Chrysosporium. Appl Environ Microbiol 1992:3605-13.

[20] Glenn JK, Gold MH. Purification and characterization of an extracellular $\mathrm{Mn}(\mathrm{II})$-dependent peroxidase from the lignin-degrading basidiomycete, Phanerochaete chrysosporium. Arch Biochem Biophys 1985;242(2):329-41.

[21] D'Annibale A, Crestini C, DiMattia E, Sermanni GG. Veratryl alcohol oxidation by manganese-dependent peroxidase from Lentinus edodes. $\mathbf{J}$ Biotechnol 1996:231-9.

[22] Mielgo I, Lopez C, Moreira MT, Feijoo G, Lema JM. Oxidative degradation of azo dyes by manganese peroxidase under optimized conditions. Biotechnol Prog 2003:325-31.

[23] Ulrich R, Nuske J, Scheibner K, Spantzel J, Hofrichter M. Novel haloperoxidase from the agaric basidiomycete Agrocybe aegerita oxidizes aryl alcohols and aldehydes. Appl Environ Microbiol 2004:4575-81.

[24] Morokutti A, Lyskowski A, Sollner S, Pointner E, Fitzpatrick TB, Kratky $\mathrm{C}$, et al. Structure and function of $\mathrm{YcnD}$ from Bacillus subtilis, a flavincontaining oxidoreductase. Biochemistry 2005:13724-33.

[25] Ander P, Messner K. Oxidation of 1-hydroxybenzotriazole by laccase and lignin peroxidase. Biotechnol Tech 1998:191-5. 
[26] Wariishi H, Valli K, Gold MH. Manganese(II) oxidation by manganese peroxidase from the basidiomycete Phanerochaete. Kinetic mechanism and role of chelators, chrysosporium. J Biol Chem 1992:23688-95.

[27] Rafii F, Cerniglia CE. Comparison of the Azoreductase and Nitroreductase from Clostridium-Perfringens. Appl Environ Microbiol 1993: $1731-4$.
[28] Zimmermann T, Gasser F, Kulla HG, Lesinger T. Comparison of two bacterial azoreductases acquired during adaption to growth on azo dyes. Arch Microbiol 1984;138:37-43.

[29] Zimmermann T, Kulla HG, Leisinger T. Properties of purified Orange II azoreductase, the enzyme initiating azo dye degradation by Pseudomonas KF46. Eur J Biochem 1982:197-203. 